\title{
Correlation Between Adenosine Triphosphate Levels, Dopamine Release and Electrical Activity in the Carotid Body: Support for the Metabolic Hypothesis of Chemoreception
}

\author{
ANA OBESO, LAURA ALMARAZ and CONSTANCIO GONZALEZ \\ Departamento de Fisiologia y Bioquimica, Facultad de Medicina, Unversidad de Valladolid, 47005 Valladolid (Spain)
}

(Accepted February 5th, 1985)

Key words: carotid body - chemoreceptors - adenosine triphosphate (ATP) content — dopamine release — hypox.a 2-deoxyglucose - sodium cyanide

\begin{abstract}
An unsolved issue for the arterial chemoreceptors is the mechanism by which hypoxia and other natural stimuli lead to an increase of activity in the carotid sinus nerve. According to the 'metabolic hypothesis', the hypoxic activation of the carotid body (CB) is mediated by a decrease of the ATP levels in the type I cells, which then release a neurotransmitter capable of exciting the sensory nerve endings. Using an in vitro preparation of cat $\mathrm{CB}$, we report that ATP levels in the $\mathrm{CB}$ do in fact decrease when the organs are exposed to moderate, short lasting hypoxia ( $5 \mathrm{~min} 20 \% \mathrm{O}_{2}$ ). Additionally, we found that decreases in ATP levels induced by 2-deoxyglucose $(2 \mathrm{mM})$ or sodium cyanide $(0.1 \mathrm{mM})$ are closely correlated with dopamine release from type I cells and electrical activity in the carotid sinus nerve elicited by these agents. The possible cause-effect relationship of these events is discussed.
\end{abstract}

\section{INTRODUCTION}

The carotid bodies (CBs) are a pair of chemoreceptor organs located in the area of the carotid bifurcation, which are activated by environmental low $\mathrm{O}_{2}$ pressure, low $\mathrm{pH}$ and high $\mathrm{CO}_{2}$ pressure ${ }^{17}$. Sensory nerve fibers of the carotid sinus nerve (CSN) penetrate the organ and form synaptic-like contacts with the type I cells.

As discussed in recent reviews ${ }^{3,15}$ two key problems in the understanding of the chemoreception process have been: (1) the location of the chemosensor within the $\mathrm{CB}$; and (2) the definition of the transduction mechanism(s) in biophysical and/or biochemical terms. Dealing with the first issue, the accumulated evidence in recent years favors the idea that the $\mathrm{CB}$ is a secondary receptor in Grundfest termino$\log y^{16}$, the type I cells being the chemosensors. A transmitter released at the synapse between the type I cells and the sensory nerve endings would ultimately activate the sensory nerve endings; however, the chemical identity of this transmitter is not presently established. The transduction mechanism for the CB chemoreceptors remains largely unknown, and among the hypotheses advanced for chemotransduction, the 'metabolic hypothesis' has received great attention $1,6,18,26,32$. This hypothesis rests on the observation that all metabolic poisons are powerful chemostimulants, and postulates that hypoxia, like the metabolic poisons, leads to an increase in CSN activity by producing a decrease in adenosine triphospate (ATP) levels, which in turn triggers the release of transmitter from the type I cells.

In favor of the metabolic hypothesis are the recent observations that type I cells release dopamine (DA), a putative neurotransmitter, in a dose-dependent fashion when CBs are exposed to hypoxia $^{10,12}$. On the other hand, it is well documented that: (1) ATP levels in brain slices are maintained at normal levels when the tissue is superfused with 7-10\% $\mathrm{O}_{2}$-equilibrated solutions ${ }^{20}$, which are known to strongly activate the CB chemoreceptors 7,12 ; and (2) in no other structure do metabolic poisons activate the release of neurotransmitters $19,29,30,33,34$. Therefore, a validation of the metabolic hypothesis will require that the moderate levels of hypoxia which are

Correspondence: C.G. Martinez, Departamento de Fisiologia y Bioquimica, Facultad de Medicina, Universidad de Valladolid, 47005 Valladolid, Spain. 
detected by $\mathrm{CB}$ chemoreceptors produce a decrease in the ATP levels in this organ, and that metabolic poisons are able to induce the release of putative neurotransmitters from the type I cells.

In the experiments to be described, it is shown that moderate and short-lasting hypoxia reduced the ATP levels in the CB. It is also shown that 2-deoxyglucose (2-DG) and $\mathrm{CN}^{-}$reduced the ATP content of the $\mathrm{CB}$, increased CSN activity and induced release of DA from the type I cells. These findings provide experimental support for the metabolic hypothesis of chemotransduction in this organ.

\section{MATERIAL AND METHODS}

The carotid bifurcations of adult cats $(2-3.5 \mathrm{~kg})$, anesthetized with sodium pentobarbital (30-40 $\mathrm{mg} / \mathrm{kg}$ i.p., Sigma), were removed and placed in a lucite chamber filled with ice-cold $100 \% \mathrm{O}_{2}$ equilibrated Tyrode 2 . The CBs with their nerves attached were prepared under a dissecting microscope (Leitz) for electrophysiological recording as previously described ${ }^{12}$

To study the release of DA, the preparations were first incubated for $3 \mathrm{~h}$ at $37^{\circ} \mathrm{C}$ in small vials placed in a metabolic shaker with $500 \mu \mathrm{l}$ of $100 \% \mathrm{O}_{2}$-equilibrated Tyrode containing $20 \mu \mathrm{M}$ [3H]tyrosine $(3,5-$ [ $\left.{ }^{3} \mathrm{H}\right]$ tyrosine, $20 \mathrm{Ci} / \mathrm{mmol}$; Amersham); at the end of the incubation period, the preparations were mounted in a superfusion chamber ${ }^{12}$ which allowed simultaneous recording of electrical activity in the CSN and collection of the superfusates for analysis. The released $\left[{ }^{3} \mathrm{H}\right] \mathrm{DA}$ and $\left[{ }^{3} \mathrm{H}\right]$ catechol metabolites were adsorbed on alumina at $\mathrm{pH} 8.6$ and, after thorough washing with distilled water were eluted with 1 $\mathrm{N}$ hydrocholoric acid ${ }^{35}$. Thin-layer chromatographic analysis of the eluates ${ }^{13}$ revealed that $\left[{ }^{3} \mathrm{H}\right] \mathrm{DA}$ and $\left[{ }^{3} \mathrm{H}\right]$ DOPAC accounted for more than $85 \%$ of the radioactivity present in them, the remainder being mostly $\left[{ }^{3} \mathrm{H}\right]$ tyrosine. Total $\left[{ }^{3} \mathrm{H}\right] \mathrm{DA}$ released is taken as the sum of [ $\left.{ }^{3} \mathrm{H}\right] \mathrm{DA}$ and $\left[{ }^{3} \mathrm{H}\right] \mathrm{DOPAC}$.

When ATP was to be measured, CBs were dissected free of the CSN to allow more complete removal of surrounding connective tissue. In these experiments, one $\mathrm{CB}$ from each animal was processed as control while the contralateral organ was used to test the effects of stimulation (hypoxia, 2-DG or $\mathrm{CN}^{-}$). All tissues were preincubated for $25 \mathrm{~min}$ in scintilla- tion vials at $37{ }^{\circ} \mathrm{C}$ with $5 \mathrm{ml}$ of $100 \% \mathrm{O}_{2}$-equilibrated Tyrode, and finally incubated for $5 \mathrm{~min}$ in other vials with $2 \mathrm{ml}$ of the same preincubation media (controls) or either $20 \% \mathrm{O}_{2}$-equilibrated Tyrode (hypoxic-tissues) or $100 \% \mathrm{O}_{2}$-equilibrated media containing 2 $\mathrm{mM}$ 2-DG (2-DG-treated CBs) or $10^{-4} \mathrm{M} \mathrm{CN}^{-}\left(\mathrm{CN}^{-}\right.$ treated $\mathrm{CBs}$ ). All media contained $5 \mathrm{mM}$ glucose except in the case of the 2-DG experiments, in which 5 $\mathrm{mM}$ sodium-pyruvate was substituted for glucose. At the end of the incubation period, the tissues were placed on precooled $\left(-20^{\circ} \mathrm{C}\right)$ homogenizer pestles and immediately homogenized in $200 \mu \mathrm{l}$ of ice-cold $0.6 \mathrm{~N}$ perchloric acid; the samples were centrifuged at $4{ }^{\circ} \mathrm{C}$ and the supernatants neutralized with $2.4 \mathrm{~N}$ potassium bicarbonate at $0-4{ }^{\circ} \mathrm{C}$ and centrifuged again. ATP was determined in the final supernatants either radioenzymatically ${ }^{14}$ or by a photoluminescence-based method ${ }^{4}$.

\section{RESULTS}

The ATP level found in $9 \mathrm{CBs}$ incubated with $100 \% \mathrm{O}_{2}$-equilibrated media was $4.3 \pm 0.40 \times 10^{-10}$ $\mathrm{mol} / \mathrm{CB}$. In the contralateral organs, incubated in the same media equilibrated with air, the level was $3.4 \pm$ $0.33 \times 10^{-10} \mathrm{~mol} / \mathrm{CB}(P<0.02)$. In contrast, no difference was found in 6 pairs of mice superior cervical ganglia which were treated identically (Fig. 1). This tissue was chosen for comparison because its size and shape is similar to the cat $\mathrm{CB}$, minimizing the differences in $\mathrm{O}_{2}$ diffusion in both organs. Since the same hypoxic stimulus applied for the same lenght of time evoked a 7 -fold increase in the release of [ $\left.{ }^{3} \mathrm{H}\right] \mathrm{DA}$ and a simultaneous 6-fold increase in CSN activity10,12, the data presented in Fig. 1 suggest a possible link between the decrease in the ATP levels and the activation of the CSN via the release of a neurotransmitter from the type I cells, as the metabolic hypothesis postulates.

For the hypothesis to be correct, a similar correlation between ATP levels, CSN activity and $\left[{ }^{3} \mathrm{H}\right] \mathrm{DA}$ release must be present in any situation in which the ATP content of the $\mathrm{CB}$ is lowered. The effects of $10^{-4}$ $\mathrm{M} \mathrm{NaCN}$ in the medium are shown in Fig. 2. Fig. 2A shows the typical profile of $\left[{ }^{3} \mathrm{H}\right] \mathrm{DA}$ release induced by $\mathrm{CN}^{-}$-containing medium; note the fast onset of release, reaching a maximum within $5 \mathrm{~min}$ from the start of $\mathrm{CN}^{-}$superfusion. On returning to $\mathrm{CN}^{-}$-free 


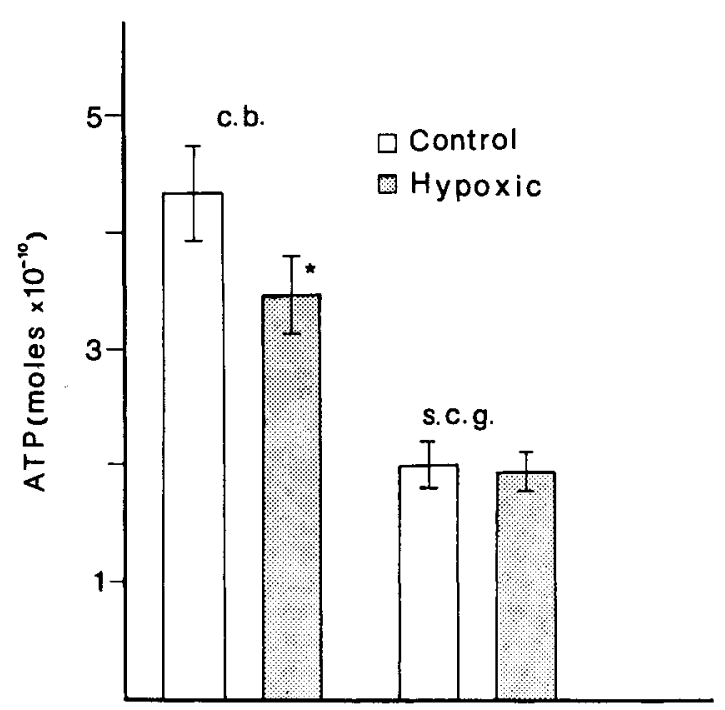

Fig. 1. Effect of $5 \mathrm{~min}$ of hypoxic incubation $\left(20 \% \mathrm{O}_{2}\right.$ equilibrated media) on the ATP content of the cat CB and mice superior cervical ganglia. ${ }^{*} P<0.02$.

solution, the release slowly decreased to the control levels. Fig. 2B shows the electrical response induced by $\mathrm{CN}^{-}$in the same preparation. Both responses were comparable to those obtained when $\mathrm{CBs}$ are superfused with low $\mathrm{O}_{2}\left(20 \% \mathrm{O}_{2}\right.$ in $\left.\mathrm{N}_{2}\right)$-containing solutions ${ }^{12}$. The average response obtained in 8 stimulation cycles from 4 experiments, expressed as multiples of control, was $3.8 \pm 0.77$ for $\left[{ }^{3} \mathrm{H}\right] \mathrm{DA}$ release and $6.8 \pm 0.59$ for CSN activity (Fig. 2C). Finally, when $\mathrm{CBs}$ were incubated for $5 \mathrm{~min}$ in the presence of $10^{-4} \mathrm{M} \mathrm{CN}^{-}$, ATP levels decreased to $55 \%$ of that in contralateral control organs $(P<0.02$; Fig. 2D).

Since both hypoxia and $\mathrm{CN}$ - should decrease ATP content by impairing its production, it was of great interest to see if a reduction in the ATP levels produced by increasing ATP expenditures also increased both electrical activity in the $\mathrm{CSN}$ and $\left[{ }^{3} \mathrm{H}\right] \mathrm{DA}$ release from the type I cells. As shown in Fig. $3 \mathrm{~A}$ and $\mathrm{B}$, the addition of 2-DG to the superfusion media ( $2 \mathrm{mmol} / \mathrm{l})$ increased both parameters in a similar way as $\mathrm{CN}^{-}$ and hypoxia. However, the time course of these increases is slowed, probably reflecting different mechanisms of action. In Fig. 3C are shown the averaged responses for $\left[{ }^{3} \mathrm{H}\right] \mathrm{DA}$ release and maximum $\mathrm{CSN}$ activity obtained from 6 experiments. Fig. 3D shows that the ATP content in $4 \mathrm{CBs}$ incubated for $5 \mathrm{~min}$ in $2 \mathrm{mM} 2-\mathrm{DG}$ decreased by $38 \%$ compared to contralateral control organs $(P<0.02)$. This concentration
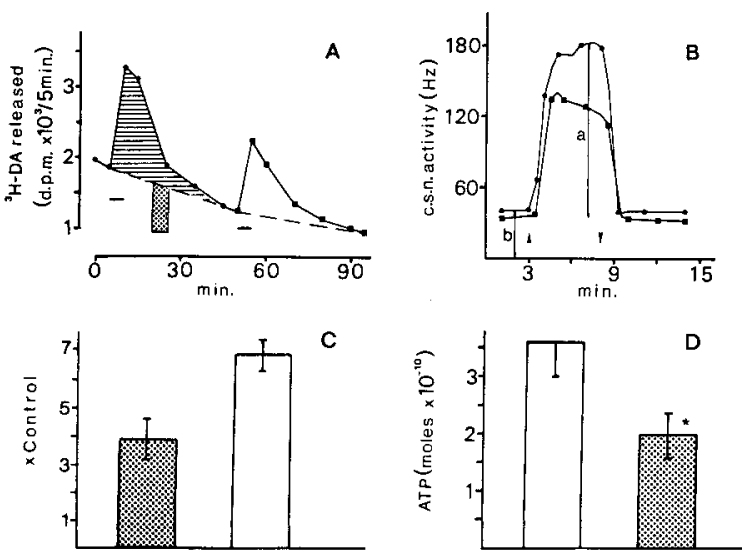

Fig. 2. A: time course of $\mathrm{CN}^{-}\left(10^{-4} \mathrm{M}\right)$ induced release of $\left[{ }^{3} \mathrm{H}\right] \mathrm{DA}$ in a single experiment in which $\mathrm{CN}^{-}$was applied twice during $5 \mathrm{~min}$ (horizontal bars) defining two stimulation cycles. The dashed area represents actual release induced by the first application of $\mathrm{CN}^{-}$, the stippled bar represents mean interpolated basal release during the first stimulation cycle for a $5 \mathrm{~min}$ period (identical to the stimulation period). Dashed area divided by stippled bar equals induced release in times over the control. B: carotid sinus nerve activity in response to $10^{-4} \mathrm{M} \mathrm{CN}^{-}$ applied for 5 min (between arrows, same experiment as A). One curve (solid circles) corresponds to first application of $\mathrm{CN}^{-}$ and the other curve (solid squares) to the second. a represents maximum activity induced by $\mathrm{CN}^{-}$in the first application. $\mathrm{b}$ represents basal activity prior to the $\mathrm{CN}^{-}$application; $\mathrm{a} / \mathrm{b}$ equals induced activity in times over the control. C: averaged responses for $10^{-4} \mathrm{M} \mathrm{CN}^{-}$expressed as times over the control. Stippled bar represents release of [ $\left.{ }^{3} \mathrm{H}\right] \mathrm{DA}$; open bar represents electrical activity. D: ATP content in 6 control CBs (mean \pm S.E.M., open bar) and in their contralaterals incubated for 5 min with $10^{-4} \mathrm{M} \mathrm{CN}^{-}(\text {stippled bar })^{*} P<0.02$.
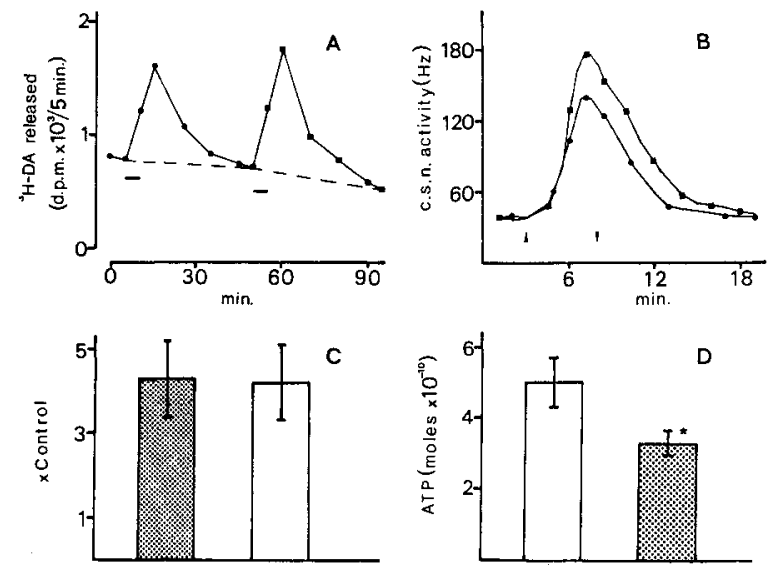

Fig. 3. Same as in Fig. 2 where the CBs are superfused (A-C) for 5 min with a solution containing $2 \mathrm{mM} 2-\mathrm{DG}$. D shows the ATP content found in 4 control CBs and in their contralaterals incubated for $5 \mathrm{~min}$ in the presence of $2 \mathrm{mM} 2-\mathrm{DG}$. ${ }^{*} P<0.02$. 
of 2-DG was chosen because it represents a stimulus of about the same strength as $10^{-4} \mathrm{M} \mathrm{CN}^{-}$.

\section{DISCUSSION}

The data presented here generally validate the metabolic hypothesis of chemoreception and point towards a link between decrease in ATP levels, secretion of putative neurotransmitters and activation of the CSN. The ATP content of the cat CB is approximately $4 \times 10^{-10} \mathrm{~mol} /$ organ. With a mean weight of $500 \mu \mathrm{g}^{9}$, and with intracellular water close to $40 \%$ of weight (personal observation), the ATP concentration in the $\mathrm{CB}$ is calculated to be $2.5 \times 10^{-3}$ $M$. This concentration is similar to that reported for rat brain ${ }^{20}$, and liver ${ }^{31}$ and mouse superior cervical ganglia (this paper).

As shown in Fig. 1, the ATP content of the CB decreased $21 \%$ with moderate hypoxic stimulation, while there was no change in ATP in the superior cervical ganglion. The ATP content of brain tissue is also more resistant to hypoxia, and thus rat brain slices and synaptosomes maintain normal ATP levels even after 30 min of incubation with a $7 \% \mathrm{O}_{2}$ equilibrated media ${ }^{20}$. The exquisite sensitivity of CB ATP levels to hypoxia could be related to the presence in the type I cells of a cytochrome oxidase with low affinity for oxygen ${ }^{24}$. This would suggest that the decrease in CB ATP levels should arise from the specific chemosensitive tissue (i.e. the type I cells). Taking into account that this specific tissue represents about $50 \%$ of CB volume 22 , a $21 \%$ decrease in ATP content in the whole organ should be an underestimation of the real ATP depletion in the type I cells. In contrast, the 38-45\% decrease in ATP content observed with 2-DG and $\mathrm{CN}^{-}$should result from a homogeneous reduction in ATP in all CB structures. These considerations suggest that the ATP reduction in type I cells might be quite similar in all 3 experimental situations. This would be consistent with the observation that $\mathrm{CN}^{-}$and 2-DG produce about the same increase in CSN activity and $\left[{ }^{3} \mathrm{H}\right] \mathrm{DA}$ release as the hypoxic stimulus used in these experiments ${ }^{12}$.

\section{REFERENCES}

1 Anichkov, S.V. and Belenkii, M.L., Pharmacology of the Carotid Body Chemoreceptors, Macmillan, New York, 1963.
It remains to be shown whether these 3 parameters (ATP levels, $\left[{ }^{3} \mathrm{H}\right] \mathrm{DA}$ release and $\mathrm{CSN}$ activity) are linked in a causal relationship, as the metabolic hypothesis would suggest. If this indeed were the case, then the decrease in ATP levels in the type 1 cells should lead to the activation of a $\mathrm{Ca}^{2+}$ conductance, because the release of [ $\left.{ }^{3} \mathrm{H}\right] \mathrm{DA}$ induced by hypoxia ${ }^{12}$ and 2-DG and $\mathrm{CN}^{-}$is dependent on the presence of extracellular $\mathrm{Ca}^{2+}$ (unpublished observations). Whatever the mechanism of this linkage, it seems to be specific for this chemosensitive organ because in other structures the secretion process is not activated by hypoxia or metabolic poisons $8,19,33,34$ despite drastic reductions in ATP content ${ }^{30}$. Alternatively, these effects may be due to two parallel but independent processes, but this would require that 2-DG, applied for only $5 \mathrm{~min}$, has another action besides the reduction in ATP content.

The relationship between release of $\left[{ }^{3} \mathrm{H}\right] \mathrm{DA}$ and activity in the CSN is controversial; exogenously applied DA has been found to be inhibitory, excitatory or both, depending on the dose, the animal species and the preparation ${ }^{21,25,36}$ (see McQueen ${ }^{23}$ for a review). Others have stressed that the real problem with DA actions in the CB is whether exogenously applied amine has the same action as the endogenously released substance. In fact, it has been recently suggested ${ }^{5,27}$ that endogenous DA may well be excitatory in the cat $\mathrm{CB}$. This suggestion is supported by the findings reported in this paper and by the observations previously published that hypoxia ${ }^{11,12}$ and low $\mathrm{pH}^{28}$ induce proportional increases in both synthesis and release of $\left[{ }^{3} \mathrm{H}\right] \mathrm{DA}$ and electrical activity in the CSN. Nonetheless, it must be recalled that type I cells contain many other putative neurotransmitters ${ }^{9}$.

\section{ACKNOWLEDGEMENTS}

We thank Professor B. Herreros for his valuable commentaries in the preparation of the manuscript. This work was supported by a grant from the C.A.I.C.T. of Spain.

2 Baron, M. and Eyzaguirre, C., Effects of temperature on some membrane characteristics of carotid body cells, Am. J. Physiol., 233 (1977) (Cell Physiol. 2) C35-C46.

3 Belmonte, C. and Gonzalez, C., Mechanisms of chemoreception in the carotid body: possible models. In H. Acker 
and R.G. O'Regan (Eds.), Physiology of the Peripheral Arterial Chemoreceptors, Elsevier, Amsterdam, 1983, pp. 197-220.

4 Brown, A.M., ATP and ATPase determination in red blood cells. In J.C. Ellory and J.D. Young (Eds.), Red Cell Membranes - A Methodological Approach, Academic Press, London, 1982, pp. 223-238.

5 Docherty, R.J., The effects of benzotropine and pargyline on response of cat carotid chemoreceptors to sodium cyanide, acetylcholine and dopamine, J. Physiol. (London), 292 (1979) 53p.

6 Erhan, B., Mulligan, E. and Lahiri, S., Metabolic regulation of aortic chemoreceptor responses to $\mathrm{CO}_{2}$, Neurosci. Lett., 24 (1981) 143-147.

7 Eyzaguirre, C. and Koyano, H., Effects of hypoxia, hypercapnia and $\mathrm{pH}$ on the chemoreceptor activity of the carotid body in vitro, J. Physiol. (London), 178 (1965) 385-409.

8 Farnebo, L.O., Release of monoamines evoked by field stimulation-studies on some ionic and metabolic requirements, Acta Physiol. Scand., Suppl. 371 (1971) 19-27.

9 Fidone, S. and Gonzalez, C., Peripheral chemoreceptors: initiation and control of discharge. In J.G. Widdicombe (Ed.), Handbook of Physiology, Respiration System, Am. Physiol. Soc., Washington D.C., 1984, in press.

10 Fidone, S., Gonzalez, C. and Yoshizaki, K., Synthesis and release of catecholamines by the cat carotid body: effects of hypoxic stimulation, Soc. Neurosci. Abstr., 4 (1979) 402.

11 Fidone, S., Gonzalez, C. and Yoshizaki, K., Effects of hypoxia on catecholamine synthesis in rabbit carotid body in vitro, J. Physiol. (London). 333 (1982) 81-91.

12 Fidone, S., Gonzalez, C. and Yoshizaki, K., Effects of low oxygen on the release of dopamine from the rabbit carotid body in vitro, J. Physiol. (London), 333 (1982) 93-110.

13 Fleming, R.H. and Clark, W.G., Quantitative thin-layer chromatographic estimation of labeled dopamine and norepinephrine, their precursors and metabolites, J. Chromatogr., 52 (1972) 305-312.

14 Gonzalez, C. and Garcia-Sancho, J., A sensitive assay for ATP, Anal. Biochem., 114 (1981) 285-87.

15 Gronblad, M., Function and structure of the carotid body, Med. Biol., 61 (1983) 229-248.

16 Grundfest, H., The general electrophysiology of input membrane in electrogenic excitable cells. In W.R. Loewenstein et al. (Eds.), Handbook of Sensory Physiology. Vol. I, Principles of Receptor Physiology, Springer, New York, 1971, pp. 135-165.

17 Heymans, C.M., Bouckaert, J.J. and Dautrebande, L., Sinus carotidien et reflexes respiratoires, II. Influences respiratoires reflexes de l'acidose, de l'alcalose, de l'anhydride carbonique, de l'ion hydrogène et de l'anoxemie: sinus carotidiens et échanges respiratoires dans les poumons et au delà des poumons, Arch. Int. Pharmacodyn. Ther., 39 (1930) 400-408.

18 Joels, $\mathrm{N}$. and Neil, E., The idea of a sensory transmitter. In R.W. Torrance (Ed.), Arterial Chemoreceptors, Blackwell, Oxford, 1968, pp. 153-178.

19 Kirpekar, S.M., Prat, J.C. and Yamamoto, H., Effects of metabolic inhibitors on norepinephrine release from the perfused spleen of the cat, J. Pharmacol. Exp. Ther., 172 (1970) 342-350.
20 Ksiezak, H.J. and Gibson, G., Oxygen dependence of glucose and acetylcholine metabolism in slices and synaptosomes from rat brain, J. Neurochem., 37 (1981) 305-314.

21 Llados, F. and Zapata, P., Effects of dopamine analogues and antagonists on carotid chemosensors in situ, J. Physiol. (London), 274 (1978) 487-499.

22 McDonald, D.M., Peripheral chemoreceptors: Structurefunction relationships of the carotid body. In T.F. Hornbein (Ed.), The Lung Biology in Health and Disease, Vol. $X$, The Regulation of Breathing. Marcel Dekker, New York, 1981,pp. 105-319.

23 McQueen, D., Pharmacological aspects of putative transmitters in the carotid body. In H. Acker and R.G. O'Regan (Eds.), Physiology of the Peripheral Arterial Chemoreceptors, Elsevier, Amsterdam, 1983, pp. 149-196.

24 Mills, E., Metabolic aspects of chemoreceptor function. In M.J. Purves (Eds.), The Peripheral Arterial Chemoreceptors, Cambridge University Press, 1975, pp. 373-381.

25 Monti-Bloch, L. and Eyzaguirre, C., A comparative physiological and pharmocoligal study of cat and rabbit carotid body chemoreceptors. Brain Research, 193 (1980) 449-470.

26 Mulligan, E. and Lahiri, S., Dependence of carotid chemoreceptor stimulation by metabolic agents on $\mathrm{PaO}_{2}$ and $\mathrm{PaCO}_{2}$, J. Appl. Physiol., 50 (1981) 884-891.

27 Nolan, W.F., Donnelly, D.F., Smith, E.J. and Dutton, E.R., Inhibition of carotid chemoreception by haloperidol in vitro, Fed. Proc. Fed. Am. Soc. Exp. Biol., 43 (1984) 813

28 Rigual, R., Gonzalez, E., Fidone, S, and Gonzalez, C., Effects of low $\mathrm{pH}$ on synthesis and release of catecholamines in the cat carotid body in vitro, Brain Research, 309 (1984) 178-181

29 Rubin, R.P., Calcium and Cellular Secretion, Plenum Press, New York, 1982.

30 Rutledge, C.O., Effect of metabolic inhibitors and ouabain on amphetamine- and potassium-induced release of biogenic amines from isolated brain tissue, Biochem. Pharmacol., 27 (1978) 511-516.

31 Soling, H.D., Anion transport through the inner mitochondrial membrane. Site of regulation of gluconeogenesis? In F. Lundquist and N. Tystrup (Eds.), Regulation of Hepatic Metabolism, Academic Press, New York, 1974, pp. 48-61.

32 Torrance, R.W., Prolegomena. In R.W. Torrance (Ed.), Arterial Chemoreceptors, Blackwell, Oxford, 1968, pp. $1-40$

33 Vizi, E.S., Stimulation by inhibition of $\left(\mathrm{Na}^{+}-\mathrm{K}^{+}-\mathrm{Mg}^{2+}\right)-\mathrm{ac}-$ tivated ATP-ase, of acetylcholine release in cortical slices from rat brain, J. Physiol. (London), 226 (1972) 95-117.

34 Vizi, E.S., Release mechanisms of acetylcholine and the role of $\mathrm{Na}^{+}-\mathrm{K}^{+}$-activated ATP-ase. In P.G. Waser (Ed.), Cholinergic Mechanisms, Raven Press, New York, 1975, pp. 199-211.

35 Weil-Malherbe, H., Determination of catecholamines. In D. Glick (Ed.), Analysis of Biogenic Amines and their Related Enzymes, Interscience Publishers, New York, 1971, pp. 119-152.

36 Zapata, P., Effects of dopamine on carotid chemo- and baroreceptors in vitro, J. Physiol. (London), 244 (1975) 235-251. 